\title{
Hemodynamic effects of cardiotomy suction blood
}

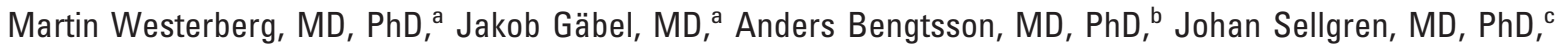 \\ Ola Eidem, ECCP, ${ }^{a}$ and Anders Jeppsson, MD, $\mathrm{PhD}^{\mathrm{a}}$
}

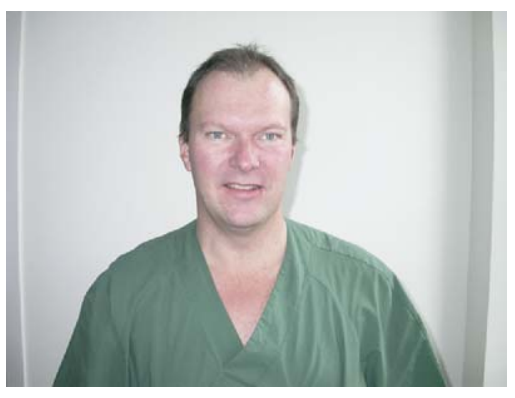

Dr Westerberg
From the Departments of Cardiothoracic Surgery $^{\mathrm{a}}$ and Anesthesia and Intensive Care, ${ }^{\mathrm{c}}$ Sahlgrenska University Hospital, Gothenburg, Sweden, and the Departments of Anesthesia and Intensive Care, ${ }^{\mathrm{b}}$ Eastern Hospital, Gothenburg, Sweden.

This study was supported by Gothenburg Medical Association, Sahlgrenska University Hospital, and Capio AB, Gothenburg, Sweden.

Received for publication Aug 2, 2005; revisions received Nov 23, 2005; accepted for publication Dec 12, 2005.

Address for reprints: Anders Jeppsson, MD, $\mathrm{PhD}$, Department of Cardiothoracic Surgery, Sahlgrenska University Hospital, SE41345 Göteborg, Sweden (E-mail: anders. jeppsson@vgregion.se).

J Thorac Cardiovasc Surg 2006;131:1352-7 $0022-5223 / \$ 32.00$

Copyright (C) 2006 by The American Association for Thoracic Surgery

doi:10.1016/j.jtcvs.2005.12.067
Objective: Cardiac surgery induces a systemic inflammatory activation, which in severe cases is associated with peripheral vasodilation and hypotension. Cardiotomy suction blood contains high levels of inflammatory mediators, but the effect of cardiotomy suction blood on the vasculture is unknown. We investigated the effect of cardiotomy suction blood on systemic vascular resistance in vivo and whether cell-saver processing of suction blood affects the vascular response.

Methods: Twenty-five patients undergoing coronary surgery (mean age, $68 \pm 2$ years; $80 \%$ men) were included in a prospective randomized study. The patients were randomized to retransfusion of cell-saver processed $(n=13)$ or cell-saver unprocessed $(\mathrm{n}=12)$ suction blood during full cardiopulmonary bypass. Mean arterial blood pressure was continuously registered during retransfusion, and systemic vascular resistance was calculated. Plasma concentrations of tumor necrosis factor $\alpha$, interleukin 6 , and complement factor $\mathrm{C} 3$ a were measured in suction blood.

Results: Retransfusion of cardiotomy suction blood induced a transient reduction in systemic vascular resistance in all patients. The peak reduction was significantly less pronounced in the group receiving cell-saver processed blood $(-12 \% \pm 2 \%$ vs $-28 \% \pm 3 \%, P=.001)$. There was a significant correlation between tumor necrosis factor $\alpha$ concentration in retransfused cardiotomy suction blood and peak reduction of systemic vascular resistance $(r=0.60, P=.002)$.

Conclusions: The results suggest cardiotomy suction blood is vasoactive and might influence vascular resistance and blood pressure during cardiac surgery. The observed vasodilation is proportional to the inflammatory activation of suction blood and can be reduced by processing suction blood with a cell-saving device before retransfusion.

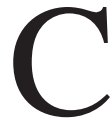
ardiac surgery induces a systemic inflammatory response characterized by complement activation and release of proinflammatory and anti-inflammatory cytokines. ${ }^{1,2}$ The inflammatory response might be subclinical but is, in its most severe forms, associated with peripheral vasodilation and hypotension. ${ }^{3-6}$ Sustained hypotension can result in insufficient end-organ perfusion and ischemic complications.

Cardiotomy suction (CS) during cardiopulmonary bypass (CPB) is used to maintain an appropriate hemoglobin concentration and to reduce the need for homologous blood transfusions. However, there is a pronounced inflammatory activity in CS blood, and retransfusion of CS blood has therefore been suggested to contribute to the postoperative inflammatory response. ${ }^{7-11}$ Inflammatory mediators, such as cytokines and complement split products, have vasoactive properties, ${ }^{12-14}$ and CS blood might therefore influence vascular resistance. However, to our knowledge, no previous investigation has studied whether CS blood has hemodynamic effects when retransfused. Our first aim was thus to investigate potential hemodynamic effects of CS blood in vivo, and in addition, we sought to investigate whether potential effects could be related to concentrations of inflammatory medi- 


$$
\begin{aligned}
& \text { Abbreviations and Acronyms } \\
& \begin{aligned}
\mathrm{CABG} & =\text { coronary artery bypass grafting } \\
\mathrm{CPB} & =\text { cardiopulmonary bypass } \\
\mathrm{CS} & =\text { cardiotomy suction } \\
\mathrm{IL} & =\text { interleukin } \\
\mathrm{SVR} & =\text { systemic vascular resistance } \\
\mathrm{TNF} & =\text { tumor necrosis factor }
\end{aligned}
\end{aligned}
$$

ators in CS blood. Finally, we wanted to study whether potential hemodynamic effects are reduced if the CS blood is processed with a cell-saver before retransfusion. For these purposes, a prospective randomized study was performed in patients undergoing coronary artery bypass grafting (CABG) with CPB.

\section{Patients and Methods \\ Patients}

Inclusion criteria were as follows: age of 40 to 80 years, 2- or 3 -vessel coronary disease with angina pectoris and appropriate coronary anatomy for $\mathrm{CABG}$, left ventricular ejection fraction of greater than $40 \%$, and no other significant disorders. Exclusion criteria were as follows: preoperative use of steroids or nonsteroidal anti-inflammatory drugs, intraoperative administration of vasoactive or anti-inflammatory drugs, and signs of significant peripheral arterial disease.

The study group consisted of 25 patients with a mean age of $68 \pm 2$ years, $80 \%$ of whom were men. Patient characteristics are shown in Table 1. All patients were operated on with CPB. The Research Ethics Committee of the Medical Faculty, University of Gothenburg, approved the study protocol.

\section{Clinical Management}

The patients were premedicated with flunitrazepam and morphinescopolamine. Anesthesia was induced with 3 to $5 \mathrm{mg} / \mathrm{kg}$ thiopental, followed by $0.1 \mathrm{mg} / \mathrm{kg}$ pancuronium. Fentanyl was administered in incremental doses up to a total amount of 8 to $10 \mu \mathrm{g} / \mathrm{kg}$ before sternotomy. The patients were normoventilated with oxygen in air (fraction of inspired oxygen, 0.4-0.5), and enflurane was used as an inhalational agent both before and after CPB. Propofol was administered during CPB. Before cannulation, heparin (300 IU/kg; Lövens, Ballerup, Denmark) was administered and supplemented as required to maintain an activated clotting time of more than 480 seconds. The extracorporeal circuit was primed with approximately $1700 \mathrm{~mL}$ of Ringer-acetate (Fresenius-Kabi, Uppsala, Sweden), $200 \mathrm{~mL}$ of mannitol (Fresenius-Kabi), $100 \mathrm{~mL}$ of Tribonate (Fresenius-Kabi), and 7500 IU of heparin. CPB was performed with a hollow-fiber membrane oxygenator. A hard-shell reservoir (with blood-air interface) with separate chambers for venous return and CS blood was used (D 903 Avant; Dideco, Mirandola Modena, Italy). The reservoir design makes it possible to collect CS blood and allows blood sampling before the content is returned to the venous reservoir. Aprotinin was not used.

The operations were performed with a standard nonpulsatile CPB technique with moderate hypothermia (nasopharyngeal tem-
TABLE 1. Preoperative and perioperative variables (mean + standard error of the mean)

\begin{tabular}{lccc}
\hline & $\begin{array}{c}\text { Cell-saver } \\
\text { group }\end{array}$ & $\begin{array}{c}\text { Unprocessed } \\
\text { group }\end{array}$ & $\boldsymbol{P}$ value \\
\hline $\mathrm{n}$ & 13 & 12 & \\
Age (y) & $67 \pm 2$ & $69 \pm 2$ & .33 \\
Sex (M/F) & $10 / 3$ & $10 / 2$ & .54 \\
Ejection fraction & $0.53 \pm 0.03$ & $0.52 \pm 0.04$ & .85 \\
Aortic clamp time (min) & $45 \pm 5$ & $41 \pm 4$ & .53 \\
CPB time (min) & $90 \pm 8$ & $80 \pm 6$ & .45 \\
No. of grafts & $3.5 \pm 0.3$ & $3.1 \pm 0.3$ & .41 \\
\hline
\end{tabular}

$C P B$, Cardiopulmonary bypass.

perature, $34{ }^{\circ} \mathrm{C}$ ) and hemodilution (hematocrit, $20 \%$ to $30 \%$ ). A standard flow of $2.4 \mathrm{~L} \cdot \mathrm{min}^{-1} \cdot \mathrm{m}^{-2}$ was used. Cardioprotection was achieved with cold blood cardioplegia. No topical cooling was used. Weaning off CPB was performed after rewarming to a rectal temperature of at least $36^{\circ} \mathrm{C}$.

\section{Study Protocol and Analyses}

The patients were randomly allocated into 2 groups. In the first group CS blood was evacuated from the reservoir and processed in a cell-saver device (autoLog; Medtronic, Minneapolis, Minn) before retransfusion $(n=13)$. In the second group CS blood was retransfused without further processing $(n=12)$. The cell-saver produced approximately $135 \mathrm{~mL}$ of washed, packed red blood cells. Ringer-acetate was added to the processed blood to maintain a retransfusion volume and hematocrit value comparable with those of the unprocessed group. All CS blood was retransfused during full CPB immediately before weaning by opening the hatch between the CS reservoir chamber and the venous return reservoir.

Concentrations of the proinflammatory cytokines tumor necrosis factor (TNF) $\alpha$ and interleukin (IL) 6 and complement factor C3a were measured in the separate CS reservoir before and after cell-saver processing. Samples for cytokine and complement analyses were collected into tubes with ethylenediamine tetraacetic acid and placed immediately on ice. The aliquots were centrifuged immediately, and the resultant plasma was stored at $-70^{\circ} \mathrm{C}$ until analysis. TNF- $\alpha$, IL-6, and C3a levels were determined with commercially available enzyme-linked immunosorbent assay kits by using double-antibody enzyme-linked immunosorbent assays, according to the manufacturer's instructions. The following assays were used: TNF- $\alpha$ and IL-6, R\&D systems; C3a, Quidel (San Diego, Calif). Hemoglobin content and hematocrit value were also analyzed in CS blood before retransfusion.

Mean arterial blood pressure was continuously registered from the arterial line and stored with 200 samples per second by using a computer technique (Acknowledge; BioPac Systems, Santa Barbara, Calif). An investigator blinded to group affiliation analyzed the files.

\section{Calculations}

Systemic vascular resistance (SVR) was calculated according to the formula $S V R=80 \times($ MAP/cardiac output $)$, where cardiac output equals the CPB flow rate. Plasma concentrations of TNF- $\alpha$, 


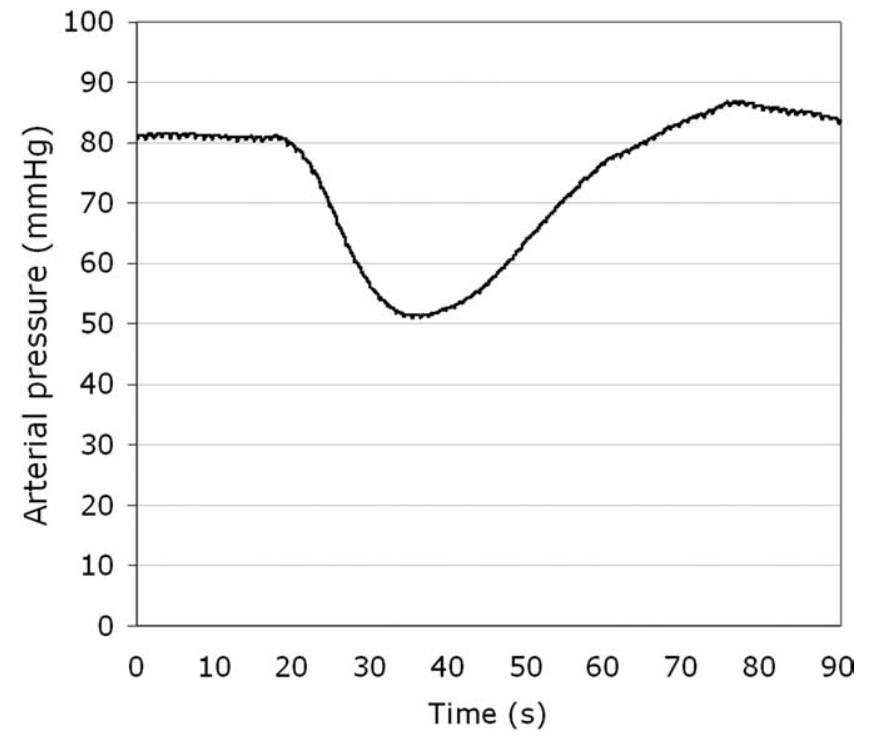

Figure 1. Representative sample of mean arterial pressure during retransfusion of unprocessed cardiotomy suction blood.

IL-6, and C3a in suction blood were corrected for hematocrit by relating measurements to a standard hematocrit value of $40 \%$ according to the following formula:

\section{Corrected concentration $=$ Measured concentration}

$\times$ (Standard hematocrit/Measured hematocrit $){ }^{7}$

\section{Statistics}

The nonparametric Mann-Whitney $U$ test (continuous variables) and the Fisher exact test (categoric variables) were used to compare the groups. Differences within a group were compared with the paired nonparametric Wilcoxon test. Comparisons were made both with percentage change from baseline and with absolute values. Correlation was analyzed with the Spearman rank sum test. All the results are expressed as the mean \pm standard error of the mean.

\section{Results}

\section{Clinical Course}

One patient in the cell-saver group had a perioperative stroke. All other patients recovered normally after surgical intervention and were discharged from the hospital within 7 days. None of the patients received transfusion of homologous blood, predonated autologous blood, or any other blood product during the study.

\section{Baseline Variables}

There were no statistically significant differences between the cell-saver group and the unprocessed group with respect to age, sex, ejection fraction, aortic clamp time, or number of grafts (Table 1).

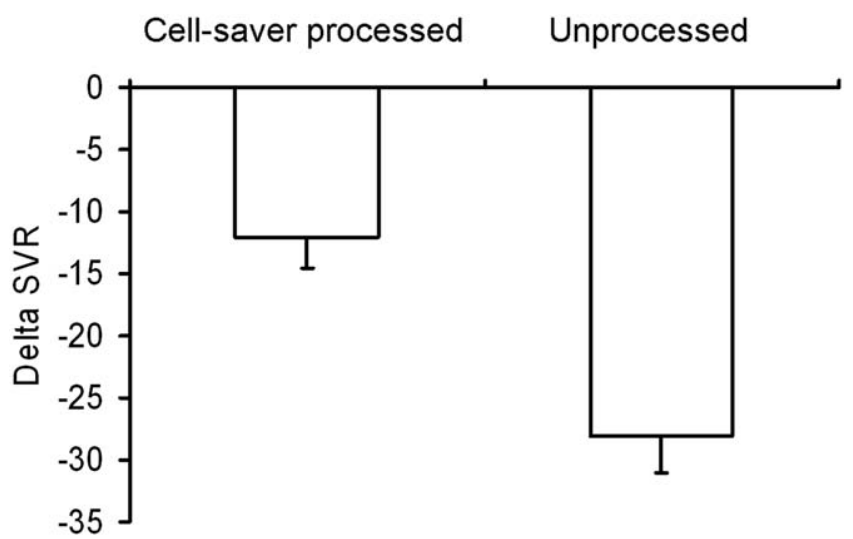

Figure 2. Relative changes in systemic vascular resistance (SVR) during retransfusion of cell-saver processed or cell-saver unprocessed cardiotomy suction blood (mean \pm standard error of the mean). There was a significant difference between the 2 groups $(P=.001)$.

\section{CS Blood and SVR}

The mean volume of collected CS blood during the operation was $477 \pm 36 \mathrm{~mL}$. The mean volume of retransfused CS blood was $403 \pm 17 \mathrm{~mL}$, and the mean hematocrit value was $15 \% \pm 2 \%$. The mean arterial pressure before retransfusion was $67 \pm 3 \mathrm{~mm} \mathrm{Hg}$. Rapid retransfusion of CS blood induced a transient reduction in SVR immediately after retransfusion in all patients (Figures 1 and 2). The mean time to minimum SVR was $42 \pm 2$ seconds.

\section{Inflammatory Mediators and SVR}

Plasma concentrations of TNF- $\alpha$, IL- 6 , and C3a were significantly increased in unprocessed CS blood compared with systemic plasma concentrations at the same time point (TNF- $\alpha:+280 \% \pm 154 \%, P<.001$; IL-6: $+1268 \% \pm$ $445 \%, P<.001$; C3a: $+473 \% \pm 136 \%, P<.001)$. The absolute values were $10.1 \pm 2.4$ versus $4.5 \pm 1.1 \mathrm{pg} / \mathrm{mL}$ $(P=.010)$ for TNF- $\alpha, 600 \pm 174$ versus $100 \pm 46 \mathrm{pg} / \mathrm{mL}$ $(P<.001)$ for $\mathrm{IL}-6$, and $5294 \pm 953$ versus $1107 \pm 107$ $\mathrm{ng} / \mathrm{mL}(P<.001)$ for C3a.

There were statistically significant correlations between TNF- $\alpha$ concentrations in retransfused CS blood and $\Delta \%$ SVR $(r=0.60, P=.002, \mathrm{y}=-0.15$ to $0.02 \mathrm{x}$; Figure 3$)$ and between C3a and $\Delta \%$ SVR $(r=0.43, P=$ $.043, \mathrm{y}=-0.14$ to $\left.6 \times 10^{-5} \mathrm{x}\right)$. No correlation between IL-6 and $\Delta \%$ SVR was detected $(r=0.22, P=.31)$.

\section{Effects of Cell-saver Processing}

Perioperative bleeding and retransfusion. The mean volume of collected CS blood during the operation was higher in the cell-saver group $(551 \pm 55 \mathrm{~mL})$ compared with that in the unprocessed group $(397 \pm 37 \mathrm{~mL}, P=$ .009). The mean volume of retransfused CS blood did not 


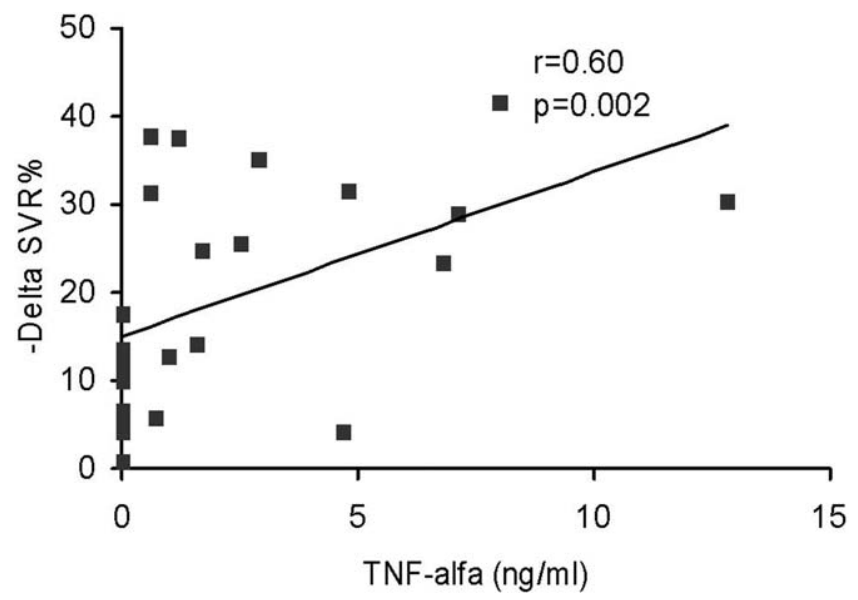

Figure 3. Correlation between plasma levels of TNF- $\alpha$ in retransfused cardiotomy suction blood and relative changes in systemic vascular resistance.

differ between the groups $(401 \pm 1 \mathrm{~mL}$ in the cell-saver group and $405 \pm 36 \mathrm{~mL}$ in the unprocessed group, $P=.25$ ). There was no significant difference in hematocrit values of the retransfused blood between the groups $(17 \% \pm 2 \%$ in the cell-saver group and $14 \% \pm 2 \%$ in the unprocessed group, $P=.20$ ).

Inflammatory activation in CS blood. Cell-saver processing significantly reduced concentrations of TNF- $\alpha$ $(-38 \% \pm 11 \%, P=.012)$ and $\mathrm{C} 3 \mathrm{a}(-70 \% \pm 14 \%, P=$ $.016)$ in CS blood. In absolute values TNF- $\alpha$ levels decreased from $7.5 \pm 2.5$ to $3.5 \pm 1.6 \mathrm{pg} / \mathrm{mL}(P=.012)$ and C3a levels decreased from $4337 \pm 1087$ to $1757 \pm 913$ $\mathrm{ng} / \mathrm{mL}(P=.021)$. IL-6 levels tended to decrease $(-19 \% \pm$ $34 \%, P=.27)$, from $633 \pm 315$ to $229 \pm 81 \mathrm{pg} / \mathrm{mL}(P=.13)$.

Hemodynamic effects. Baseline SVR (immediately before retransfusion of CS blood) was comparable between the cell-saver group and the unprocessed group (1086 \pm 82 vs $1115 \pm 77$ dynes $\cdot \mathrm{s}^{1} \cdot \mathrm{cm}^{-5}, P=.58$ ).

During retransfusion of CS blood, the vasodilation was less pronounced in the group receiving cell-saver processed blood compared with that seen in the group receiving unprocessed blood $(\Delta \mathrm{SVR}=-140 \pm 34 \mathrm{vs}-326 \pm 50$ dynes $\left.\cdot \mathrm{s}^{1} \cdot \mathrm{cm}^{-5}, P=.006\right)$. The relative reduction in $\Delta \mathrm{SVR}$ is depicted in Figure 2.

\section{Discussion}

The main findings in the present study were as follows: (1) rapid retransfusion of CS blood induced a transient reduction in SVR; (2) the reduction in SVR was proportional to the inflammatory activation in CS blood; and (3) processing suction blood with a cell-saving device before retransfusion reduced the effect on the vasculature.

\section{Inflammation and Hemodynamics}

Cardiac surgery induces an inflammatory response. The inflammatory response can result in postoperative complications, such as prolonged ventilation and renal failure, ${ }^{6,15-17}$ and has also been associated with myocardial injury. ${ }^{18}$ In its most severe forms, the systemic inflammatory response is associated with peripheral vasodilation and hypotension, ${ }^{1-6,13,19}$ and the inflammatory activation has also been connected with a vasoplegic syndrome after cardiac surgery. ${ }^{3-5}$

Systemic levels of cytokines and complement factors are reduced during and early after CABG when $\mathrm{CS}$ is discarded, ${ }^{7}$ which demonstrates that CS contributes to the inflammatory activation during and after cardiac surgery. CS blood contains high levels of cytokines (IL-1, IL-6, and TNF- $\alpha$ ) and complement split factors (C3a and sC5b$9),{ }^{7,10,11,20-23}$ which all have vasoactive properties. ${ }^{12-14}$ Theoretically, CS blood can thus contribute to perioperative vasodilation, but to our knowledge, this issue has not previously been investigated.

We hypothesized that CS blood is vasoactive and established an in vivo method to investigate the effect in patients undergoing CABG with CPB. CS blood was collected in a separate reservoir during the operation and retransfused immediately before weaning of CPB during continuous blood pressure registration. The heart was completely unloaded, and thus a potential reduction in mean arterial pressure can be regarded as an effect caused by vasodilation. From the measured arterial pressure, the change in SVR was calculated. Retransfusion of unprocessed CS blood in this model caused a prompt reduction in systemic resistance $(-28 \%)$, which thus demonstrates the vasoactive properties of CS blood. It is conceivable that this is an effect of the inflammatory activity in CS blood because the magnitude of the reduction in SVR correlated to the concentrations of TNF- $\alpha$ in CS blood (Figure 3) and, to a lesser degree, to C3a. TNF- $\alpha$, IL-6, and C3a are not only markers of inflammation but also have their own important pathophysiologic effects. ${ }^{24,25}$ TNF- $\alpha$ increases stress hormone release and neutrophil adhesion, causes myocardial depression, and stimulates production of other cytokines, such as IL-6 and IL-8. TNF- $\alpha$ has also vasoactive properties and has been demonstrated to stimulate production of inducible nitric oxide synthase. $^{2,26}$ One might thus speculate that the marked immediate effect of CS blood on SVR is mediated by nitric oxide.

The hemodynamic effects of CS blood might be attenuated or even absent if the suction blood is retransfused over a more extensive period. However, when we designed the present study, it was not known whether CS blood had any hemodynamic effects at all. The study was therefore intentionally designed to investigate the potential hemodynamic effects of CS blood in an artificial experimental set up with sudden retransfusion. If this design demonstrates hemody- 
namic effects, it would motivate further studies with different protocols and hypotheses to study the clinical importance.

\section{Cell-saver Processing}

Cell-saver processing reduces the amount of inflammatory mediators in CS blood significantly. ${ }^{8,27,28}$ However, depending on the device, $5 \%$ to $20 \%$ of cytokines remain after processing. ${ }^{27,28}$ In the present investigation cell-saver processing decreased TNF- $\alpha$ and C3a concentrations in CS blood and reduced the systemic vasodilation by approximately $60 \%$ compared with unwashed blood (12\% vs $28 \%$ ). The subtotal reduction of inflammatory substances might explain why the reduction in SVR in the present study was not entirely abolished in the cell-saver group. Alternatively, other properties of the retransfused blood volume (viscosity and temperature) that are not influenced by cell-saver processing might have an effect on vascular resistance.

\section{Limitations}

SVR can be influenced by different factors (eg, sympathetic activation, drugs, blood viscosity, and temperature). ${ }^{29,30}$ Considering this, there are some limitations in the study design that need to be discussed. The hematocrit value of the retransfused blood was lower than that in the patient, indicating a lower viscosity. This might partly explain the reduction in SVR in both groups. However, because neither the hematocrit value nor the retransfused volume (constant pump flow) differed significantly between the processed and the unprocessed groups, this does not explain the marked intergroup difference caused by cell-saver processing. The temperature of the retransfused blood was not measured specifically but is probably somewhat lower than in the systemic circulation and similar between the 2 groups.

The dilution of the CS blood in the cell-saver group after processing can be debated. The rationale was as mentioned above, that it has been shown that blood viscosity can influence SVR. ${ }^{29}$ To avoid differences in viscosity, we chose to replace the plasma with Ringer-acetate in the cell-saver group. One might argue that this was artificial and might have influenced the results. However, a pilot study was performed with the same experimental set up as in the present study, and in this model infusion of a comparable amount of Ringer-acetate did not influence vascular resistance.

Another issue is whether stasis of the CS blood in the reservoir might affect the levels of inflammatory mediators. This cannot be ruled out with the present study design, but it should be emphasized that the blood was continuously collected during $\mathrm{CPB}$, and therefore the final content in the reservoir is a mix of suction blood collected over approximately 45 minutes. Again, the handling was identical in both groups, and this cannot explain intergroup differences.

\section{Clinical Implications}

CS blood is often suctioned directly into the venous reservoir and retransfused continuously, diluted in the circulating blood volume. Vascular effects of CS blood might thus be insignificant or even undetectable in routine cardiac surgery. However, in high-risk patients or in patients undergoing long or complicated operations with extensive intraoperative bleeding, the observed effect of CS blood on SVR might be of greater importance. Accordingly, the results of the present study do not indicate that the present handling of CS blood should be revised but propose that the importance of retransfusion of CS blood is investigated in studies with clinical end points.

The observation that processing CS blood with a cellsaving device significantly reduced the effect on SVR supports, at first sight, the use of cell-saving devices perioperatively, at least when considerable intraoperative bleeding can be expected. However, cell-saver processing might also have potential harmful effects on the blood, such as bleeding diathesis related to loss of platelets and coagulation proteins, which might counteract beneficial effects. Again, clinical studies are warranted.

We appreciate the skilful assistance in laboratory analyses by Maria Tylman.

\section{References}

1. Wan S, LeClerc JL, Vincent JL. Inflammatory response to cardiopulmonary bypass: mechanisms involved and possible therapeutic strategies. Chest. 1997;112:676-92.

2. Paparella D, Yau TM, Young E. Cardiopulmonary bypass induced inflammation: pathophysiology and treatment. An update. Eur J Cardiothorac Surg. 2002;21:232-44.

3. Levin RL, Degrange MA, Bruno GF, Del Mazo CD, Taborda DJ, Griotti JJ, et al. Methylene blue reduces mortality and morbidity in vasoplegic patients after cardiac surgery. Ann Thorac Surg. 2004;77: 496-9.

4. Gomes WJ, Carvalho AC, Palma JH, Teles CA, Branco JN, Silas MG, et al. Vasoplegic syndrome after open heart surgery. J Cardiovasc Surg (Torino). 1998;39:619-23.

5. Gomes WJ, Erlichman MR, Batista-Filho ML, Knobel M, Almeida DR, Carvalho AC, et al. Vasoplegic syndrome after off-pump coronary artery bypass surgery. Eur J Cardiothorac Surg. 2003;23:165-9.

6. Sablotzki A, Friedrich I, Muhling J, Dehne MG, Spillner J, Silber RE, et al. The systemic inflammatory response syndrome following cardiac surgery: different expression of proinflammatory cytokines and procalcitonin in patients with and without multiorgan dysfunctions. Perfusion. 2002;17:103-9.

7. Westerberg M, Bengtsson A, Jeppsson A. Coronary surgery without cardiotomy suction and autotransfusion reduces the postoperative systemic inflammatory response. Ann Thorac Surg. 2004;78:54-9.

8. Svenmarker S, Engstrom KG. The inflammatory response to recycled pericardial suction blood and the influence of cell-saving. Scand Cardiovasc J. 2003;37:158-64.

9. Aldea GS, Soltow LO, Chandler WL, Triggs CM, Vocelka CR, Crockett GI, et al. Limitation of thrombin generation, platelet activation, and inflammation by elimination of cardiotomy suction in patients undergoing coronary artery bypass grafting treated with heparin-bonded circuits. J Thorac Cardiovasc Surg. 2002;123:742-55.

10. Flom-Halvorsen HI, Ovrum E, Tangen G, Brosstad F, Ringdal MA, Oystese R. Autotransfusion in coronary artery bypass grafting: disparity in laboratory tests and clinical performance. J Thorac Cardiovasc Surg. 1999;118:610-7. 
11. Johnell M, Elgue G, Larsson R, Larsson A, Thelin S, Siegbahn A. Coagulation, fibrinolysis, and cell activation in patients and shed mediastinal blood during coronary artery bypass grafting with a new heparin-coated surface. J Thorac Cardiovasc Surg. 2002;124: 321-32.

12. Minghini A, Britt LD, Hill MA. Interleukin-1 and interleukin-6 mediated skeletal muscle arteriolar vasodilation: in vitro versus in vivo studies. Shock. 1998;9:210-5.

13. Menasche P, Haydar S, Peynet J, Du Buit C, Merval R, Bloch G, et al. A potential mechanism of vasodilation after warm heart surgery. The temperature-dependent release of cytokines. J Thorac Cardiovasc Surg. 1994;107:293-9.

14. Doguet F, Litzler PY, Tamion F, Richard V, Hellot MF, Thuillez C, et al. Changes in mesenteric vascular reactivity and inflammatory response after cardiopulmonary bypass in a rat model. Ann Thorac Surg. 2004;77:2130-7.

15. Cremer J, Martin M, Redl H, Bahrami S, Abraham C, Graeter T, et al. Systemic inflammatory response syndrome after cardiac operations. Ann Thorac Surg. 1996;61:1714-20.

16. Rothenburger M, Soeparwata R, Deng MC, Schmid C, Berendes E, Tjan TD, et al. Prediction of clinical outcome after cardiac surgery: the role of cytokines, endotoxin, and anti-endotoxin core antibodies. Shock. 2001;16(suppl 1):44-50.

17. Asimakopoulos G, Smith PL, Ratnatunga CP, Taylor KM. Lung injury and acute respiratory distress syndrome after cardiopulmonary bypass. Ann Thorac Surg. 1999;68:1107-15.

18. Wan S, Izzat MB, Lee TW, Wan IY, Tang NL, Yim AP. Avoiding cardiopulmonary bypass in multivessel CABG reduces cytokine response and myocardial injury. Ann Thorac Surg. 1999;68:52-6.

19. Wan S, LeClerc JL, Vincent JL. Cytokine responses to cardiopulmonary bypass: lessons learned from cardiac transplantation. Ann Thorac Surg. 1997;63:269-76.

20. Spanier T, Tector K, Schwartz G, Chen J, Oz M, Beck J, et al. Endotoxin in pooled pericardial blood contributes to the systemic inflammatory response during cardiac surgery. Perfusion. 2000;15: 427-31.

21. Flom-Halvorsen HI, Ovrum E, Oystese R, Brosstad F. Quality of intraoperative autologous blood withdrawal used for retransfusion after cardiopulmonary bypass. Ann Thorac Surg. 2003;76:744-8.

22. de Haan J, Boonstra PW, Monnink SH, Ebels T, van Oeveren W. Retransfusion of suctioned blood during cardiopulmonary bypass impairs hemostasis. Ann Thorac Surg. 1995;59:901-7.

23. de Haan J, Boonstra PW, Tabuchi N, van Oeveren W, Ebels T. Retransfusion of thoracic wound blood during heart surgery obscures biocompatibility of the extracorporeal circuit. J Thorac Cardiovasc Surg. 1996;111:272-5.

24. Borish LC, Steinke JW. 2. Cytokines and chemokines. J Allergy Clin Immunol. 2003;111(suppl):S460-75.

25. Monsinjon T, Richard V, Fontaine M. Complement and its implications in cardiac ischemia/reperfusion: strategies to inhibit complement. Fundam Clin Pharmacol. 2001;15:293-306.

26. Worrall NK, Chang K, LeJeune WS, Misko TP, Sullivan PM, Ferguson TB Jr, et al. TNF-alpha causes reversible in vivo systemic vascular barrier dysfunction via NO-dependent and -independent mechanisms. Am J Physiol Heart Circ Physiol. 1997;273:H2565-74.

27. Reents W, Babin-Ebell J, Misoph MR, Schwarzkopf A, Elert O. Influence of different autotransfusion devices on the quality of salvaged blood. Ann Thorac Surg. 1999;68:58-62.

28. Amand T, Pincemail J, Blaffart F, Larbuisson R, Limet R, Defraigne JO. Levels of inflammatory markers in the blood processed by autotransfusion devices during cardiac surgery associated with cardiopulmonary bypass circuit. Perfusion. 2002;17:117-23.

29. Chen RY, Chien S. Hemodynamic functions and blood viscosity in surface hypothermia. Am J Physiol Heart Circ Physiol. 1978;235: H136-43.

30. Rubini A. Effect of perfusate temperature on pulmonary vascular resistance and compliance by arterial and venous occlusion in the rat. Eur J Appl Physiol. 2005;93:435-9. 